\title{
UMA DISCUSSÃO COM VISTAS AO DESENVOLVIMENTO DE UM SISTEMA ON LINE DE AVALIAÇÃO DO DESEMPENHO ESCOLAR: UM ESTUDO EXPERIMENTAL SOBRE AVALIAÇÃO DE DESEMPENHO ESCOLAR EM REDE
}

\author{
A DISCUSSION WITH A VIEW TO THE DEVELOPMENT OF AN ON-LINE \\ SYSTEM OF EVALUATION OF SCHOOL PERFORMANCE: AN \\ EXPERIMENTAL STUDY ON EVALUATION OF SCHOOL PERFORMANCE IN \\ NETWORK
}

RESUMO: O presente trabalho, foi realizado com objetivo de verificar o desempenho dos alunos para fins de intervenção. Empregando testes objetivos com conteúdo de matemática básica se produziu uma ferramenta de avaliação web capaz de coletar, armazenar e processar informações sobre o desempenho dos alunos durante o teste avaliativo e, com o tempo, uma análise longitudinal de sua trajetória escolar em um relatório de desempenho detalhado. Este software foi disponibilizado e aplicado aos alunos do terceiro ano do ensino médio de uma escola pública do município de Araraquara. Os procedimentos metodológicos, envolvendo a investigação teórica e o trabalho de campo desse estudo, compreenderam a criação e desenvolvimento de um software de avaliação, a organização de uma base de dados relacional, o roteiro de entrevista para professores participantes e um questionário aplicado aos alunos usuários do ambiente computacional.

PALAVRAS-CHAVE: Tecnologia de informação. Política de Avaliação. Avaliação Escolar. Avaliação Online.

\section{Introdução}

As tecnologias de processamento de informação e comunicação (TIC) encontram-se amplamente difundidas na sociedade atual. Sua incorporação às atividades cotidianas dos indivíduos promoveu uma reorganização nas relações de trabalho, de lazer, de comunicação e no relacionamento com o saber. Segundo FREIRE e SHOR (1993, p. 48), a questão atual é entender "o estabelecimento de uma relação diferente com o conhecimento e com a sociedade".

\footnotetext{
${ }^{1}$ Mestrando do Programa de Pós-Graduação em Educação Escolar da FCLAr - UNESP. E-mail: aannddrree.silva@gmail.com

${ }^{2}$ Professor Doutor no Programa de Pós-Graduação em Educação Escolar da FCLAr - UNESP. E-mail: ss.lemes2@gmail.com
} 
Ao analisar a sociedade atual, caracterizada pela presença das tecnologias, Prensky (2001), discute a emergência de grupos denominados de "nativos digitais" e "imigrantes digitais". Este autor relaciona estes dois perfis na sociedade, dizendo que os nativos digitais têm uma vida online, ou seja, tem hábitos e costumes fortemente atrelados a tecnologia, enquanto os imigrantes digitais procuram se adaptar a este novo cenário repleto de transformações e inovações tecnológicas. Logo, temos um grupo de pessoas fortemente habituadas à utilização de ferramentas tecnológicas e um grupo que possivelmente enfrentará alguns obstáculos relacionados a falta de conhecimento ou até mesmo interesse pela utilização da tecnologia. No entanto, esses obstáculos serão minimizados à medida que os aparatos tecnológicos vão se integrando definitivamente à sociedade. Neste sentido, os conhecimentos, as habilidades e competências necessárias para atuar nesta sociedade devem ser desenvolvidas pelos indivíduos.

Esta sociedade, também chamada de sociedade em rede (Castells, 1999), em se tratando de comunicação, depende da geração, processamento e transmissão de informação, com agilidade e segurança. Componentes essenciais da uma nova forma de produtividade e de poder. Assim, a informação se transforma em um elemento-chave dessa sociedade, cujas transformações sociais, técnicas, organizacionais e administrativas se tornam, em geral, condicionadas pelos desenvolvimentos desses produtos tecnológicos e suas tecnologias de informação e comunicação. Além disso, essas TIC têm se efetivado como recurso estratégico para a transformação das instituições e para a modernização da gestão. As instituições atuais, no âmbito de uma sociedade em rede, buscam "formas de organização mais flexíveis horizontais e eficientes" (MARCELO, 2012, p.25), objetivando alternativas para o "uso racional dos recursos" e "melhorias na qualidade das informações e serviços" (JORGE; PERIOTTO, 2006).

Segundo Peters (2003), ainda utilizamos tais produtos tecnológicos pensando nos métodos de ensino existentes e não conseguimos visualizar as novas possibilidades e caminhos para sua utilização. Existem inúmeros softwares educacionais que foram produzidos baseados em um sistema organizacional de educação tradicional cujo fazer pedagógico desconsidera a dinâmica das demandas do momento atual. Precisamos visualizar e implementar modelos que possibilitem uma interação mais efetiva com uma geração que almeja dominar sistemas complicados, controlar e conduzir processos. Esta situação encoraja, provoca e até incita os alunos a autoaprendizagem. 
Segundo Fountain (2005, p. 59), a tecnologia da informação tem a capacidade de manipular símbolos usados em todo tipo de trabalho e de afetar tanto a coordenação quanto os processos de produção e de tomada de decisão dentro de instituições e organizações.

Nesse contexto, a instituição escolar também é afetada pelas transformações em curso. Cada vez mais as tecnologias invadem o universo educacional e imprimem a ele novas possibilidades de reorganização. Dimensões como a gestão educacional, a administração escolar, os processos de ensino-aprendizagem e as modalidades educacionais são influenciadas intensamente pelos usos das tecnologias. Como consequência, os instrumentos com os quais a educação escolar conta para o trabalho pedagógico e de gestão não estão imunes a essa influência. A avaliação educacional e de desempenho têm um grande potencial para o emprego da tecnologia, por isso, nosso foco nesse momento é utilizar a tecnologia de banco de dados com finalidade avaliativa.

\section{Avaliação da educação escolar}

As instituições de ensino em sua maioria utilizam métodos e técnicas tradicionais de avaliação, ou seja, a verificação de resultados e a atribuição de valores numéricos e conceituais que qualificam o conhecimento (objeto) de forma relativa. Dentro dessa perspectiva a avaliação é assumida pelo professor como um instrumento de tomada de decisões que age como integrador no processo de ensino e aprendizagem.

Segundo Bloom (1971), a avaliação pode ser classificada como: formativa (controladora), somativa (classificatória) e diagnostica (analítica). A avaliação formativa tem o papel de inclusão dos conteúdos, fornecendo feedback ao aluno e ao professor a fim de encontrar formas alternativas para a recuperação da aprendizagem. A avaliação somativa, tem o papel de verificar o que realmente o aluno aprendeu fazendo comparações entre estudantes, métodos e materiais de ensino utilizados. A avaliação diagnostica está presente em dois momentos, antes e durante o processo de ensinoaprendizagem, no primeiro momento verifica se o aluno possui conhecimento específico, habilidades e competências necessárias para a realização das atividades 
propostas pelo curso e no segundo momento analisa as dificuldades e insuficiências existentes na aprendizagem.

A avaliação, nesse contexto, entre seus vários objetivos tem o papel de fornecer apoio a gestão, que por sua vez necessita, segundo Libâneo (1998) atingir alguns objetivos:

O primeiro deles é o de preparar os alunos para o processo produtivo e para a vida numa sociedade tecnocientífica informacional. Em segundo lugar, proponho o objetivo de proporcionar meios de desenvolvimento de capacidades cognitivas e operativas, ou seja, ajudar os alunos nas competências do pensar autônomo, crítico e criativo. O terceiro objetivo é a formação para a cidadania crítica e participativa. O quarto objetivo é a formação ética. É urgente que os diretores, coordenadores e professores entendam que a educação moral é uma necessidade premente da escola atual (LIBÂNEO, 1998, p.3).

Segundo Lemes (2010, p. 67), a avaliação educacional/escolar e a necessária revisão e reflexão pontual de conceitos, fundamentos e indicadores frente às demandas para a escolarização atual,

Faz com que o instrumento seja uma dimensão fundamental nas discussões amplas sobre avaliação. A adequação do instrumento avaliativo à necessidade da informação é que irá possibilitar a construção adequada do mosaico que reproduz a realidade em avaliação. É a composição integrada de diferentes instrumentos que irá possibilitar a leitura da realidade e a(s) necessidade(s) de intervenção(ões).

A partir do exposto por Lemes (2010), fica claro que a informação também se constitui para o campo educacional e, no interior deste, o avaliativo, um bem fundamental para que se tenha uma compreensão adequada da realidade educacional e da aprendizagem. Quanto maior o volume de informação possibilitada por um ou mais instrumentos de avaliação, maior será a condição para tomadas de decisão e de intervenção nos processos de escolarização.

Nas últimas décadas, a avaliação assumiu grande importância nas políticas públicas. A escola, além de se preocupar com a avaliação interna, tem também que se voltar para as avaliações externas, como o SARESP - no Estado de São Paulo; aquelas aplicadas em nível nacional (SAEB, ENEM, ENADE, Prova Brasil, entre outras) e, também, as internacionais como o PISA. Essas avaliações geram um grande número de informações sobre o desempenho do aluno e a qualidade da educação, no entanto, estas 
informações não chegam de forma satisfatória às unidades escolares para servirem como instrumentos de tomadas de decisão e/ou de intervenções na prática escolar.

Nesse contexto, há necessidade de se construir instrumentos que permitam às instituições de ensino, além de atribuir valor aos resultados verificados, analisar em amplitude e profundidade as características desses resultados. Criar um espaço para o debate sobre o desempenho observado próprio, além de permanente.

\section{Proposta de avaliações online}

Objetivando mapear e analisar as dificuldades dos alunos em relação aos conteúdos escolares, este artigo demonstra a utilização de uma aplicação web juntamente com uma base de dados que teve como objetivo coletar informações relacionadas ao desempenho do avaliando na forma de um sistema online que foi disponibilizado a uma instituição de ensino da rede pública e aos seus professores de matemática.

Esta aplicação web é um software que foi aplicado aos alunos a fim de complementar os conteúdos dados em salas aula. Esta aplicação em fase experimental de desenvolvimento, ofereceu um conjunto de questões formuladas de acordo com as habilidades e competências necessárias exigidas pelos 3 anos do ensino médio, logo algumas questões foram retiradas da prova ENEM. A escolha por utilizar algumas questões desse tipo de avaliação se deu pelo fato de que este é um meio de acesso às universidades públicas. Segue abaixo o layout da tela de geração de simulados da aplicação web. 
Figura 1:Exemplo d a apresentação das Questões

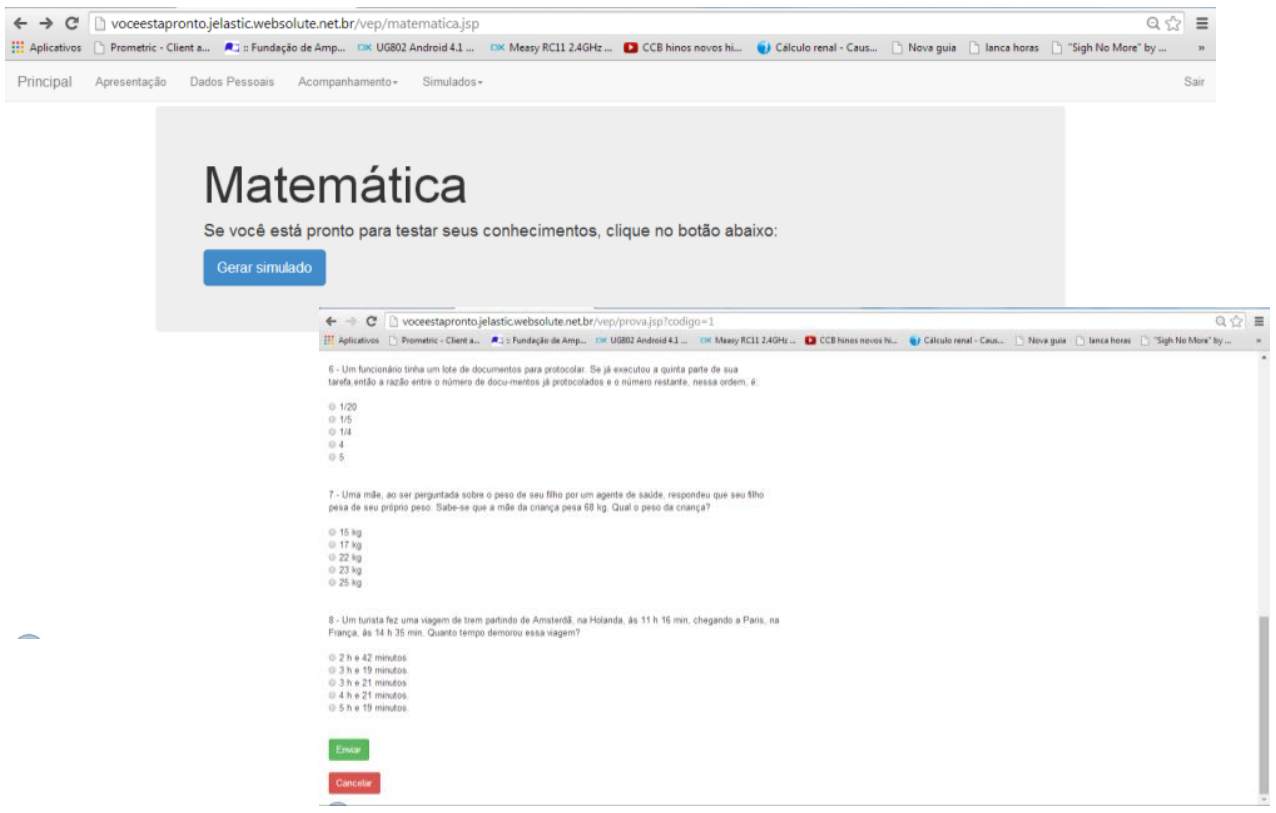

O sistema computacional desenvolvido para avaliação aplicou problematizações relacionadas à área de matemática, com intuito de oferecer feedback e orientação a estudos para as questões que indicaram insuficiência nos conhecimentos e/ou desempenho ali exigidos. O sistema ofereceu sugestões de literatura para que o aluno pudesse buscar informações e transformá-las em conhecimento, gerando um processo evolutivo onde o aluno, de forma autônoma, pudesse avaliar-se e ser avaliado constantemente no decorrer do processo ensino-aprendizagem.

Para a interface apresentada acima (Figura 1), foi utilizada a linguagem de programação JAVA e o padrão de desenvolvimento MVC (Model View Control). A interface tende a ser de fácil manuseio, interativa e recursiva. As questões da base de dados foram organizadas por níveis de dificuldade.

A aplicação foi desenvolvida utilizando o padrão UML (Unified Modeling Language), ou seja, foram criados alguns diagramas de arquitetura, a fim de proporcionar bases para o processo de desenvolvimento. Segundo Guedes (2004, p. 319), existem fases para o processo de desenvolvimento de uma aplicação Web: A integração da aplicação com o mundo externo, o comportamento da aplicação, a estrutura do sistema, os componentes do sistema e a arquitetura. 
Quanto ao banco de dados, foi utilizado o MySQL por ser um banco de dados gratuito e proporcionar ferramentas e funcionalidades necessárias para obtenção do resultado desejado. Abaixo segue o diagrama do banco de dados:

Figura 2: DER (Diagrama Entidade Relacionamento)

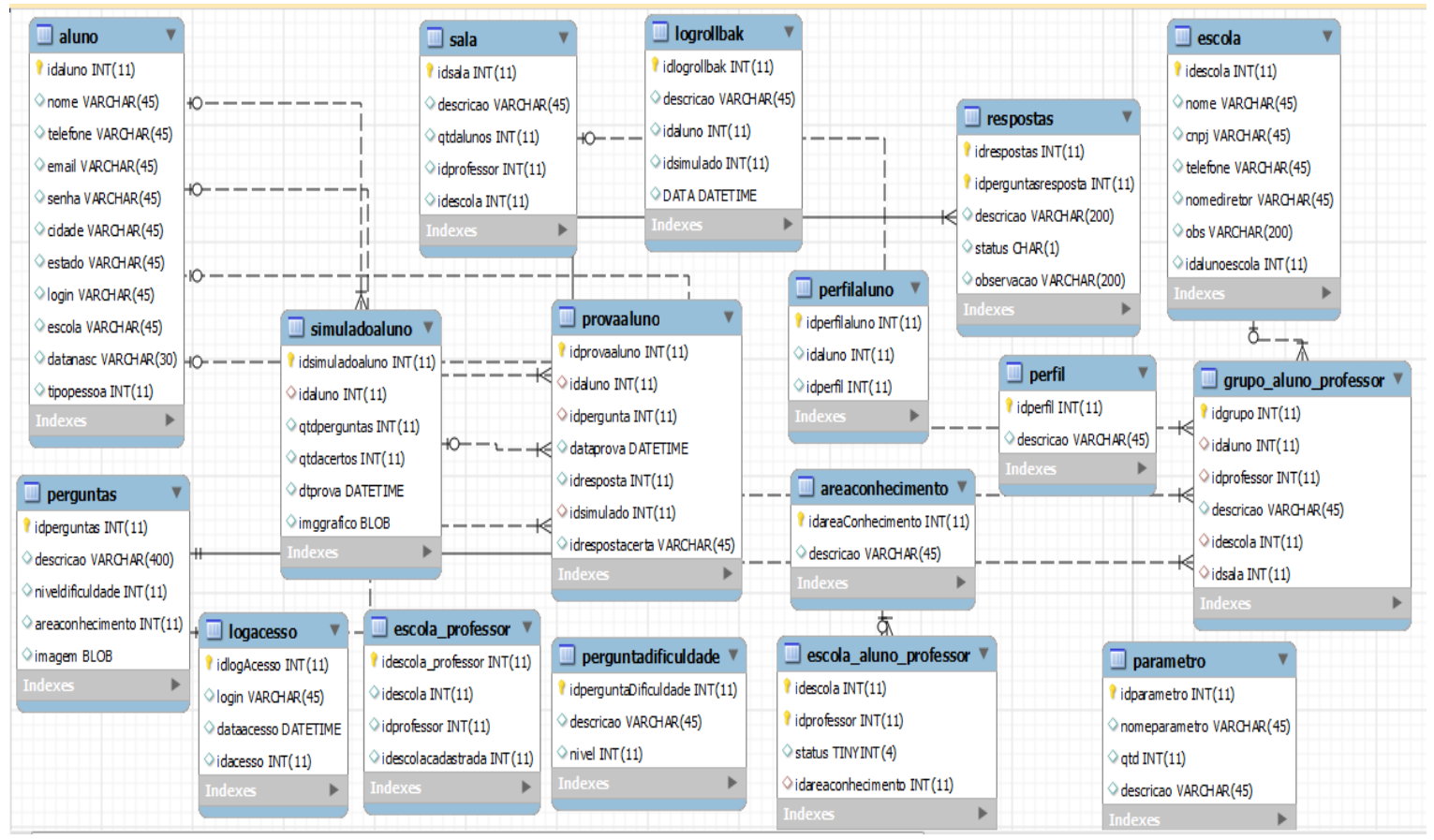

A partir do desenvolvimento desta base de dados foi possível fazer o mapeamento dos problemas em potencial, dando métricas e descritivos de análises necessárias para o estudo de melhores caminhos para alcançar o conhecimento de forma adequada. Nesta base de dados foram armazenadas informações referentes tanto ao nível de desempenho quanto algumas informações cadastrais para outras análises do aluno (como por exemplo, idade, bairro, escola, entre outros).

Os alunos que participaram da pesquisa responderam um questionário a fim de que fosse possível avaliar o uso do instrumento.

A aplicação tem o controle do número de vezes que o instrumento de avaliação são gerados pelos alunos, possibilitando saber a data e horário que estes foram realizados. Cada vez que o aluno solicita uma nova avaliação é realizada uma consulta na base de dados verificando quais perguntas já foram respondidas, após este 
procedimento a aplicação realiza uma nova consulta na base de dados colentando as perguntas que o aluno errou juntamente com novas perguntas levando em consideração a quantidade de perguntas que devem ser aplicadas (parametrização feita no banco de dados). Segue abaixo figura onde este item pode ser verificado:

Figura 3: Fluxo de Simulados

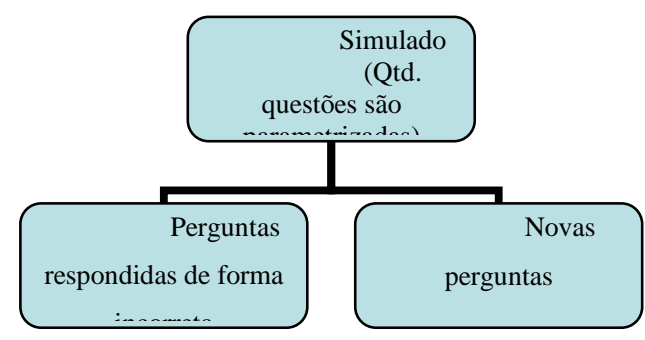

O procedimento utilizado para gerar estas questões foi desenvolvido diretamente na base de dados a fim de que a aplicação fosse mais performática, tendo em vista que esta plataforma pode ser disponibilizada para toda rede pública, inicialmente para o Estado de São Paulo.

Segue abaixo figura exemplificando a geração de gráficos automáticos pela aplicação a partir dos resultados obtidos:

Figura 4: Resultados obtidos (Visão da Escola)

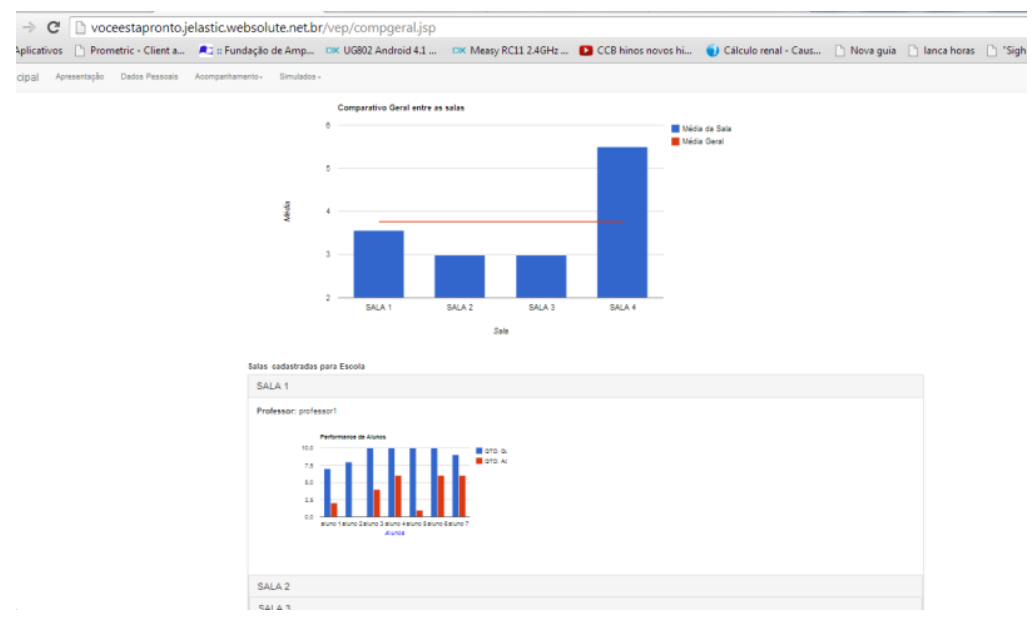

Esta aplicação proporcionou uma base de dados, que foi utilizada para coleta e análises qualiquantitativas possibilitando aprofundar e produzir conhecimentos relacionados aos processos formativos. Estes dados deram respaldo para o núcleo de 
estudos NATEC (Núcleo de Estudos em Avaliação, Tecnologia e Currículo da FCL/UNESP) em suas pesquisas.

Por também se tratar de um instrumento orientado para apoio ao professor, a fim de que este possa ter um conjunto de informações relevantes para avaliar a aprendizagem do aluno, a avaliação online serviu também para que o professor repensasse seus métodos, suas práticas e a abordagem dos conteúdos. Nesse sentido, foi fundamental discutir com os professores envolvidos os resultados da avaliação por meio de entrevistas.

É importante ressaltar que o sistema de avaliação on line é um software livre e que, apesar de se encontrar em desenvolvimento, pode ser disponibilizado na rede para uso em caráter experimental e nos favorece o aprimoramento de detalhes importantes no software.

\section{Conclusão}

Este artigo tem a finalidade de demonstrar como um web site de avaliação pode ser útil na área da educação proporcionando agilidade e praticidade na análise dos resultados obtidos. Os envolvidos são: os alunos que foram avaliados por meio de problematizações, os professores que analisaram os resultados, verificando os pontos à melhorar, as instituições que puderam por meio dos dados verificar como estão se saindo em relação a outras instituições de ensino e os pesquisadores de forma geral, possibilitando novas pesquisas e análises das informações por meio da base nos dados gerada por esta aplicação.

Com a implementação desta ferramenta foi possível mapear alguns problemas encontrados na obtenção das informações, mapeando problemas em potencial e ajudando os professores, os alunos e a instituição de ensino a trilhar caminhos para obter melhores desempenhos e resultados em avaliações oficiais do poder público.

A base de dados teve como conteúdo as questões de matemática da prova do ENEM, a fim de simplificar os testes relacionados ao mapeamento dos resultados. Contudo não existe nenhum impedimento para que esta ferramenta seja utilizada em outros tipos de avaliação em diferentes conteúdos e áreas do conhecimento. 
Por fim, a web site de avaliação online juntamente com base de dados, teve como finalidade as possíveis reorientações de aprendizagem, a autonomia dos alunos em relação à obtenção das informações e a verificação das competências adquiridas pelos alunos, professores e instituição de ensino na forma de gráficos gerados automaticamente em tempo real pela aplicação.

\section{Referências}

BLOOM, B., Hastings e Madaus (1971). Handbook on Formative and Sumative Evaluation of Student Learning. New York: McGraw-Hill Book Company. ( Manual de Avaliação Formativa e Sumativa do Aprendizado Escolar. S. Paulo: Livraria Pioneira Editora.)

BONNIOL,Jean Jacques; VIAL, Michel. Modelos de avaliação. Textos fundamentais. Trad. Claudia Schilling. Porto Alegre: Artmed Editora, 2001.

CASTELLS, M. Para o Estado-rede: e era da informação. In: BRESSER-PEREIRA, SOLA \&WILHEIM (org.). Sociedade e Estado em transformação. São Paulo: Editora Unesp, 1999.

COLL, C. Psicologia da Educação Virtual. Aprender e ensinar com as tecnologias da informação e da comunicação. Porto Alegre, 2010.

DEMO, P. Teoria e prática da avaliação qualitativa. Temas do $2^{\circ}$ Congresso Internacional sobre Avaliação na Educação. Curitiba, Paraná, 2004. p. 156-166.

FERNANDES, D. Avaliação das aprendizagens: desafios às teorias, práticas e políticas. Lisboa: Texto Editora, 2005.

FOUNTAIN, J. E. Construindo um estado virtual: tecnologia da informação e mudança institucional. Brasilia: ENAP, 2005.

FREIRE. À sombra desta mangueira. São Paulo: Olho d'Água, $1995 b$.

GATTI, B. A. O Professor e a avaliação em sala de aula. Estudos em Avaliação Educacional, n. 27, p. 97-113, jan./jun. 2003.

GOMEZ, Margarita Victoria. Educação em rede, Uma visão emancipadora, Cortez: instituto Paulo Freire, 2004, p. 161-179.

HADJI, C. A avaliação - regras do jogo: das intenções aos instrumentos. Portugal: Porto Editora, 1994.

JORGE, J. P. O.; PERIOTTO, A. J. Mudança de paradigma na gestão da informação em um setor público: tecnologia indutora, implantação e perspectivas. Anais da 
XVIII Semana do Contador. Universidade Estadual de Maringá, out. 2006. Maringá: UEM, 2006.

LEMES, Sebastião de Souza. A avaliação educacional e escolar: possibilidades para uma dimensão formuladora de políticas públicas na educação nacional. In: Cadernos de Educação. Julho/Dezembro, (Laboratório Editorial FCL/Araraquara), Araraquara, SP: 2010, p. 67.

LOUDON K. Desenvolvimento de Grandes Aplicações Web, Novatec, 2010, 328p.

LIBÂNEO, José Carlos. Coleção Educar 1. Democratização da Escola Pública. A Pedagogia crítico-social dos conteúdos. São Paulo, Loyola, 1986.

LUCKESI, C. C. Avaliação da aprendizagem na escola: reelaborando conceitos e recriando a prática. Salvador: Malabares Comunicação e Eventos, 2003.

MARCELO, C. Las tecnologias para lainnovación y lapráctica docente. In: Revista Brasileira de Educação. V. 18, nº 52 jan. mar., 2013. Rio de janeiro, Anped, 2013.

MySQL. Página oficial do banco de dados MySQL. Disponível em <http://www.mysql.com/>. Último acesso em 20/01/2007.

PETERS, O. A educação a distância em transição. Tendências e Desafios. São Leopoldo, RS, Brasil. EDITORA UNISINOS, 2003 a.

PRENSKY , M. Digital Natives, Digital Immigrants. MCB University Press, Vol. 9 No. 5, October 2001). <Disponível em http://www.marcprensky.com/writing/Prensky\%20-

\%20Digital\%20Natives, \%20Digital\%20Immigrants\%20-\%20Part1.pdf > acesso em $04 / 08 / 2013$

SETTE, S. S; AGUiAR, M. A.; SETTE J. S. A. Formação de professores em informática na educação - um caminho para mudanças. Coleção informática para mudanças da educação - MEC, 1999.

SILVA, M.; SANTOS, E. (orgs.). Avaliação da aprendizagem em educação online. São Paulo: Edições Loyola, 2011.

VIANNA, H. M. Avaliação educacional - Teoria, Planejamento, Modelos. São Paulo: IBRASA, 2000.

\section{Como referenciar este artigo}

SILVA, André Luiz da.; LEMES, Sebastião de Souza. UMA DISCUSSÃO COM VISTAS AO DESENVOLVIMENTO DE UM SISTEMA ON LINE DE AVALIAÇÃO DO DESEMPENHO ESCOLAR - Um estudo experimental sobre avaliação de desempenho escolar em rede. Revista on line de Política e Gestão Educacional, Araraquara, v.20, n.2, p. 271-281, 2016. Disponível em: <http://dx.doi.org/10.22633/rpge.v20.n2.9463>. ISSN: 1519-9029.

Submetido em: maio/2016

Aprovado em: set/2016 